\title{
Various Channel Estimation Techniques for OFDM Systems through Different Parameters
}

\author{
D.Vimala, P.Nandhini, R. Elankavi
}

\begin{abstract}
Channel estimation in OFDM system can be performed in many ways, channel estimation is the major essential component to be calculated for the wireless communication systems (such as mobile) because these are very much effective to noise than compared to the wired communications (landlines).it has loss of data due to noise, multipath degradation, fading, etc .channel estimation is the crucial task for the effective and the reliable wireless transmission. These OFDM based systems can be improved by the pilot assisted channel estimation. As compared with the various techniques we are going to conclude that which of the available techniques are more efficient to achieve the great results. Various channel estimation techniques involved in it they are LS, LMS, RLS, MMSE, NLMS, LMMS, WLs, Sparse. It may includes the complexity of building, effective to the noise, efficiency and comparing with many factors and probability of acquisition versus number of users are analyzed using QAM. Channel frequency response versus carrier no. and Error value versus the Sample performance after analyzing all the performance parameters we will conclude the best compared to other in all aspects. Sparse will have better performance as compared with the other six remaining channel estimations.
\end{abstract}

Keywords: Least Square(LS), Least Mean Square (LMS), Recursive Least Square Error (RLS), Normalized Least Mean Square (NLMS), Minimum Mean Square (MMS), Linear Minimum Mean Square(LMMS), Weighted Least Square (WLS), Sparse, Quadrate Amplitude Modulation (QAM).

\section{INTRODUCTION}

OFDM is a signaling technique used in the wireless communication .It is the best method which is in trend. Its principle is mostly used in the high speed wireless communications (4G).Wireless networking helps avoid the cost of installation through cables for homes as well as the business enterprises through various points. these wireless telecommunication networking are mainly implemented and involved in the radio frequency waves as shown in fig 1
Revised Manuscript Received on October 22, 2019.

* Correspondence Author

D.Vimala, Department of CSE, Bharath Institute of Higher Education and Research, Chennai, Tamilnadu, India.Email:vimalamuthu3@gmail.com

P.Nandhini, Department of CSE, Bharath Institute of Higher Education and Research, Chennai, Tamilnadu, India.

Email:pnandhinisuresh@gmail.com and Research, Chennai, Tamilnadu, India. Email:kavirajcse@gmail.com
R. Elankavi, Department of CSE, Bharath Institute of Higher Education
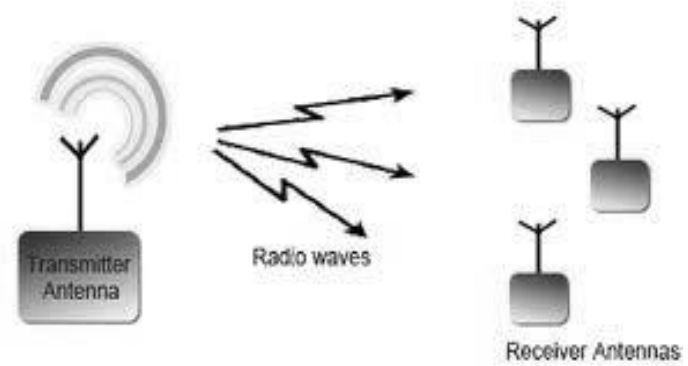

Fig 1: Wireless Communication

this implementation can be performed in the physical layer of the OSI model In OFDM the whole system is divided in to lot of orthogonal subchannels used in effective date transmissions and also uses ISI inter symbol interference.

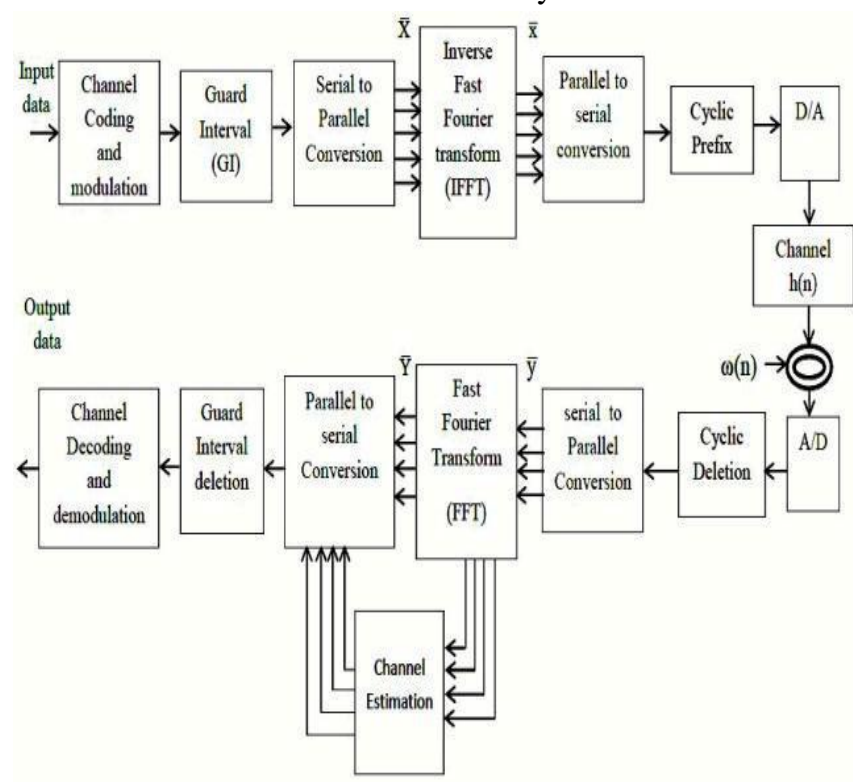

Fig.2 Block diagram of OFDM

It can be reduced by cyclic prefix.PAPR reduction reduces the usage of high power amplifier [1]. Among all these mentioned methods the Sparse is the best method to estimate the channel when compared to the other. OFDM is Orthogonal frequency division multiplexing technique which has overcome the drawbacks of the ISI model where the previous symbol has interfered in the present symbol and in OFDM it overcomes this by converting the available channel in to number of overlapping channels where it sends its own data .
Blue Eyes Intelligence Engineering 
The block diagram of OFDM can be shown in the fig 2. Many closely spaced orthogonal sub carrier signals are used to carry the each symbol on each sub carrier the reduction in the PAPR also reduces the use of high power amplifier .according to the modulation techniques of the base band signals .these obtained signals are modulated using the signal mapping subsystem it provides the good estimation of the gains and the minimum error[2] .

In general the channel estimation techniques are based on OFDM are divided in to the following categories they are blind and non blind techniques.

\section{MINIMUM MEAN SQUARE ERROR}

In this proposed approach, this priority data is taken by the PDF of the variables; and directly taken on the Bayesian calculations, thus making it superior than the other techniques posterior estimations as more of its obtained observations become available .

\section{A. LINEAR MEAN SQUARE}

In most of the cases involved, it is not at all possible to determine a perfect closed form expressions to the conditional expectation $E\{x / y\}$ is required to obtain the MMSE technique . In similar situations one possibilities is to drop the total optimal requirements and find a technique to minimize the MSE within a prescribed estimator class, as in the class of classified linear estimators technique The LMMSE is the linear minimum mean square error performs better than LS the least square technique estimator but at the cost of the complexity of the building the technique because it depends on the channel and the noise statistics [4]. The linear MMSE is the minimum mean square estimator technique is the estimator achieving the very minimum MSE that is the mean square error among all the redefined estimators of such format. Such type of techniques only depends on the first two defined terms of the PDF. So that even if it is easy to greatly take that input $x$ and output $y$ are together Gaussian in nature, as long as the assumed distribution has properly designed first two terms, it is not mandatory to make such suppositions.

\section{B.RECURSIVE LEAST SQUARE}

The most important technique that got a very efficient result till now until the advance version of it has been implemented. In Recursive least squares (RLS) adaptive filter algorithm the filter coefficients reduce the LS cost function related to the input signals.

Compared to the other techniques involved in the system for the wireless communication, the RLS technique exhibits extremely very fast convergence. Parameter however, it has this benefit comes at the cost of high computational complexity parameter. In general, the RLS technique can also be used to solve variations problem by adaptive filters

Compared to LMS, RLS algorithms have a faster convergence speed and do not exhibit the Eigen value spread problem. However, RLS algorithms have more complicated mathematical operations than LMS algorithms. The first transformation into an equivalent $0-1$ is to be the simulation parameter used in the performance analysis of channel estimation is tabulated below.

\section{MSE VS SNR RESULT}

Table 2- MSE Vs SNR performance comparison of different channel estimation

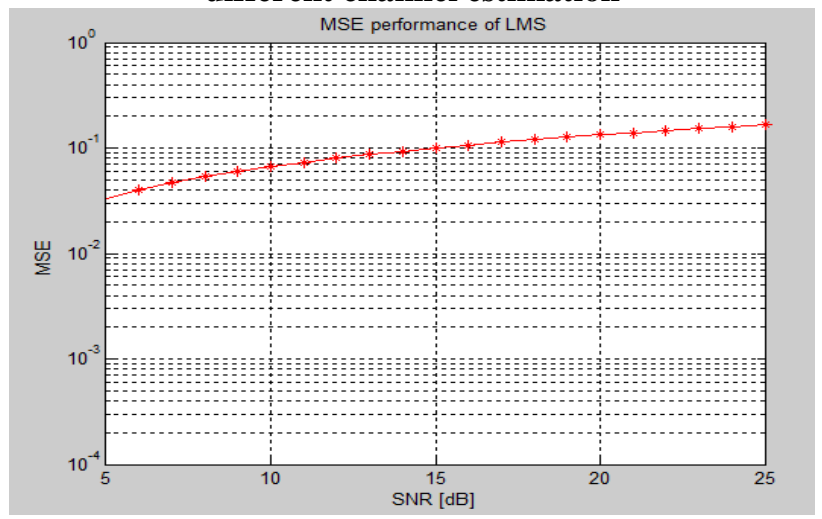

Fig. 4: MSE VS SNR PERFORMANCE OF LMS

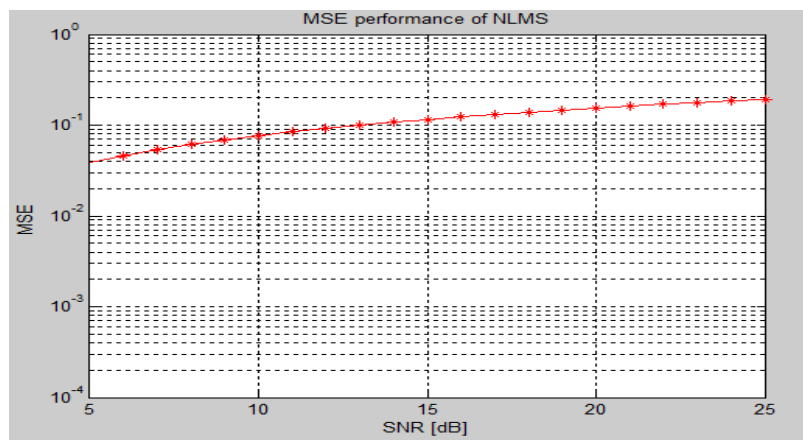

Fig. 5 :MSE VS SNR PERFORMANCE RESULTS of NLMS

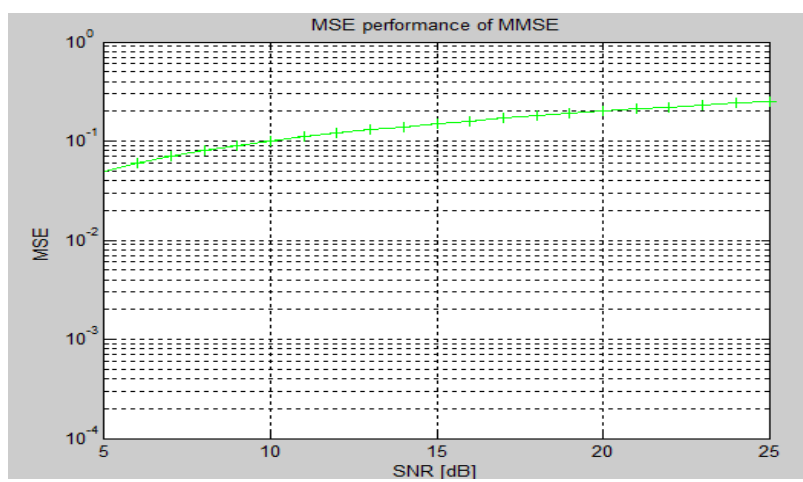

Fig. 6 :MSE VS SNR PERFORMANCE of MMSE 


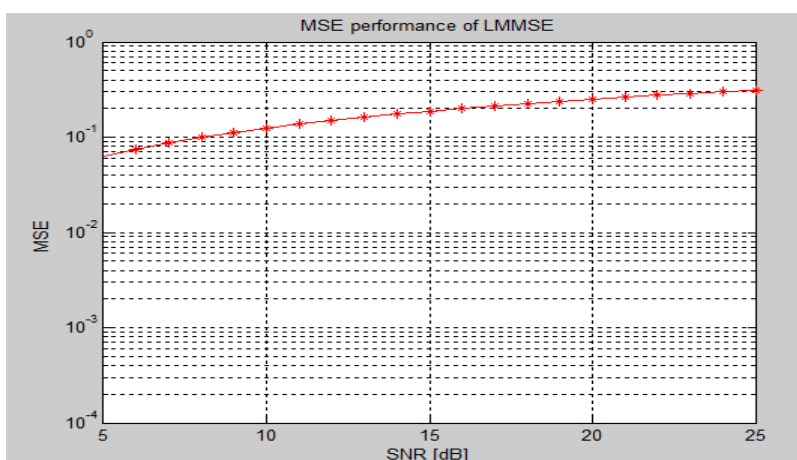

Fig. 7 :MSE VS SNR PERFORMANCE of LMMSE

Fig. 8 MSE VS SNR PERFORMANCE of RLS

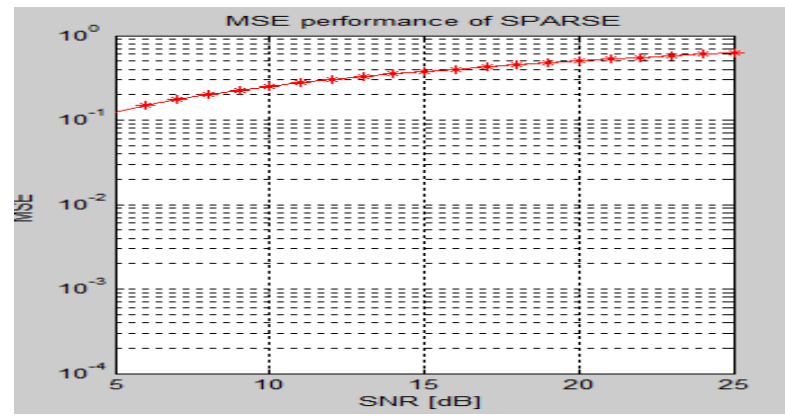

Fig. 9 :MSE VS SNR PERFORMANCE OF SPARSE

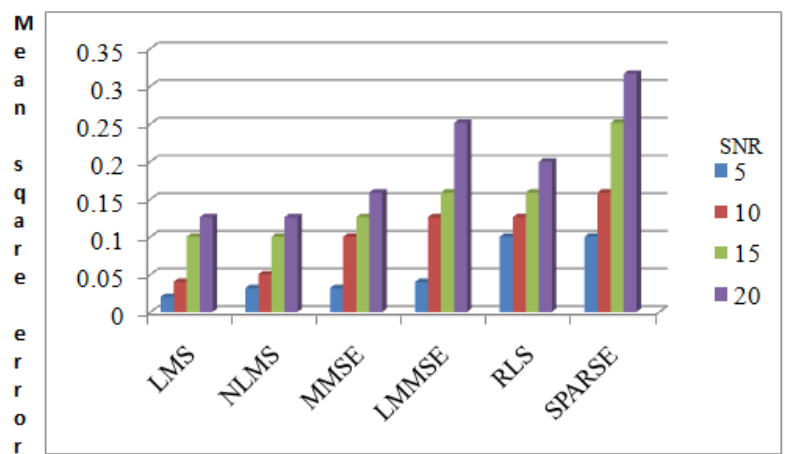

Fig.10 :MSE VS SNR PERFORMANCE COMPARISON

\section{RESULTS}

Table 3: Pilot percentage Vs $f_{D} T_{s}$ performance comparison of different channel estimation

\begin{tabular}{|c|c|c|c|c|c|c|}
\hline \multirow{2}{*}{$f_{D} I_{S}$} & \multicolumn{6}{|c|}{ PIOT PERCENTAGE } \\
\cline { 2 - 7 } & LMS & NLMS & MMSE & LMISSE & RLS & SPARSE \\
\hline 3 & 0.032 & 0.028 & 0.028 & 0.026 & 0.024 & 0.024 \\
\hline 4 & 0.04 & 0.04 & 0.038 & 0.032 & 0.027 & 0.025 \\
\hline 5 & 0.04 & 0.04 & 0.036 & 0.035 & 0.029 & 0.026 \\
\hline
\end{tabular}

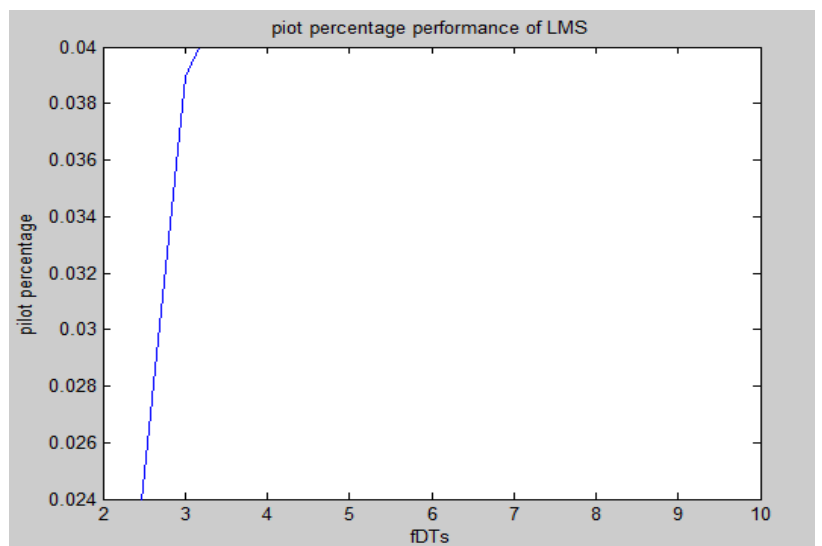

Fig. 11 :PERFORMANCE OF LMS

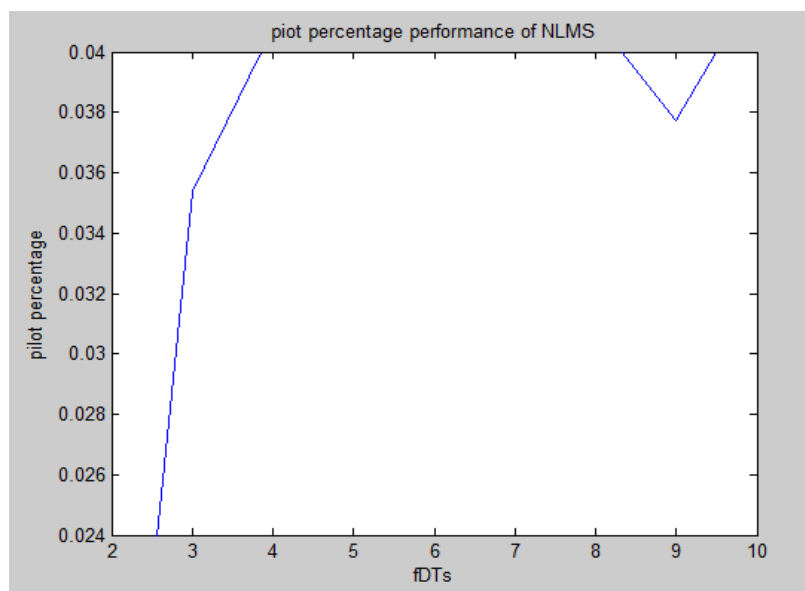

Fig. 12 PERFORMANCE OF NLMS

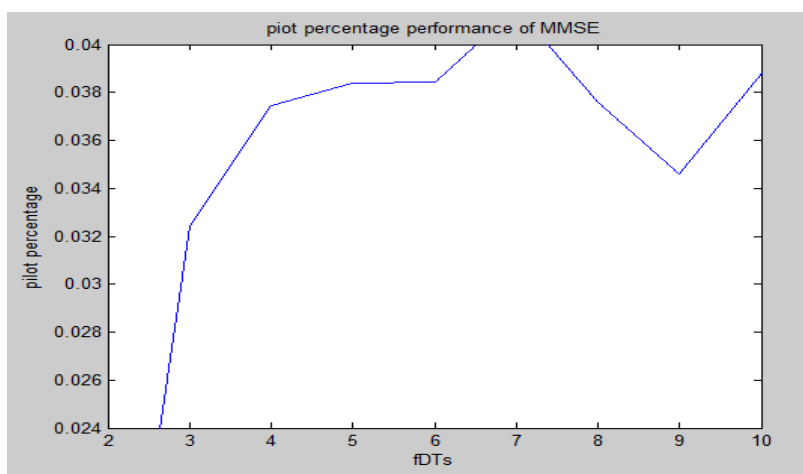

Fig. 13 PERFORMANCE OF MMSE

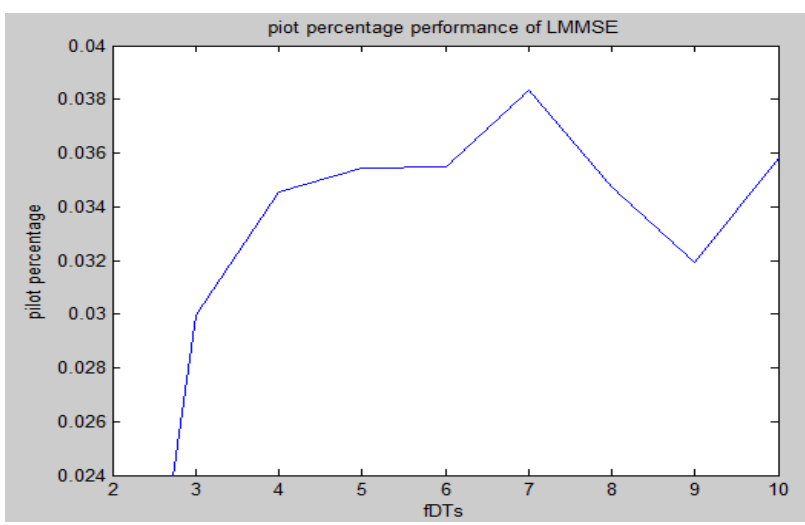

Fig. 14 PERFORMANCE OF LMMSE 


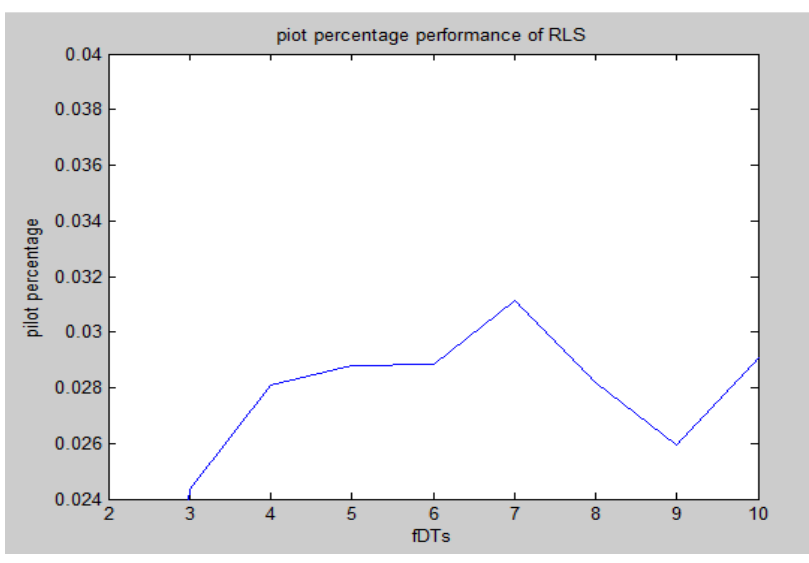

Fig.15 :PERFORMANCE OF RLS

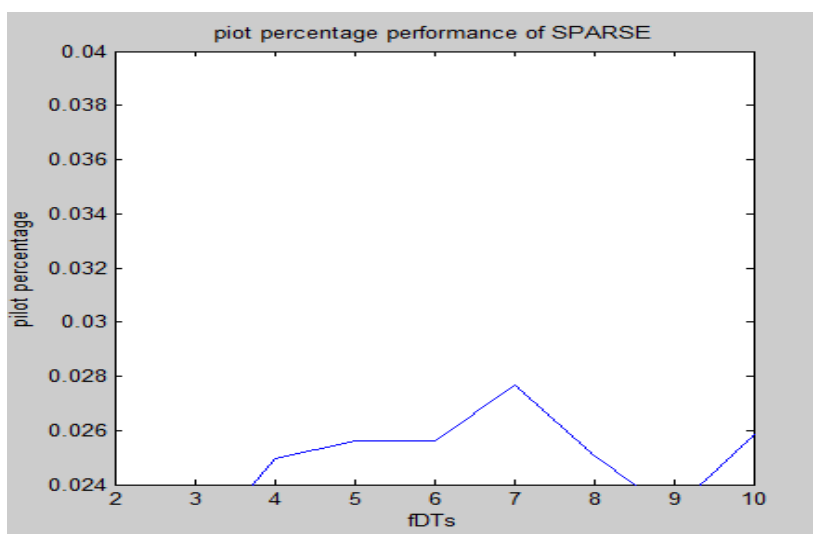

Fig. 16 PERFORMANCE OF SPARSE

from all the tabulations as well a $\mathrm{s}$ the graphical representation of all the techniques for every each parameter the sparse technique is the best channel estimation technique is better than the other three channel estimations that is the least mean square LMS, normalized least mean square NLMS, minimized mean square error MMSE, linear minimum mean square error LMMSE, recursive least square RLS .Thus with reference with ISI model the OFDM scheme is more suitable for the wireless communication to ots higher convergence and the reduced complexity in its building of the equipment [5].this scheme is getting better due to its advanced techniques for the better convergence and te better channel estimation the hybrid channel estimation can be faster estimated or converged in the combination of the 2 or 3 estimations in the LTE downlink thus the OFDM can be preferred as the LTE downlink system [6][7] Thus the use of the kalman filter is an efficient in tracking error [8].thus it is the efficient algorithm ,the complexity and the reconstruction can be made possible only by the adaptive FIR filters

\section{CONCLUSION \& FUTURE WORK}

In this whole work we at last define that sparse is the best defined technique than the other six remaining techniques they are Least mean square, Normalized least mean square, Minimum mean square error, linear minimum mean square error, recursive least square, linear square for the whole OFDM system when compared in all aspects such as the BER vs SNR performance, MSE vs no of users ,probability of

aquistion vs no of users, Pilot percentage versus fdTs, channel frequency response versus carrier no, and this all kept in reference $w$ define that Sparse is the best technique when compared with the other six remaining techniques and it is best in its less complexity as well less expensive and more efficient and the SNR is very high when compared and the BER is very low than the other. In this work the channel estimation is estimated by the several techniques and the Sparse is the best method for the channel estimation and in future new techniques may be introduced and the channel estimators with the greater mobility will be greatly used as the efficient wireless communications which indicates the OFDM block can be made that can be implemented in the receiver side of LTE system to make the wireless channel estimation more efficient.

\section{REFERENCES}

1. Kumaravel A., Meetei O.N.,An application of non-uniform cellular automata for efficient cryptography,2013 IEEE Conference on Information and Communication Technologies, ICT 2013,V-,I-,PP-1200-1205,Y-2013

2. Kumarave A., Rangarajan K., Routing alogrithm over semi-regular tessellations,2013 IEEE Conference on Information and Communication Technologies, ICT 2013,V-,I-,PP-1180-1184,Y-2013

3. Dutta P., Kumaravel A.,A novel approach to trust based identification of leaders in social networks, Indian Journal of Science and Technology,V-9,I-10,PP--,Y-2016

4. Kumaravel A., Dutta P.,Application of Pca for context selection for collaborative filtering,Middle - East Journal of Scientific Research,V-20,I-1,PP-88-93,Y-2014

5. Kumaravel A., Rangarajan K.,Constructing an automaton for exploring dynamic labyrinths,2012 International Conference on Radar, Communication and Computing, ICRCC 2012,V-,I-,PP-161-165,Y-2012

6. Kumaravel A.,Comparison of two multi-classification approaches for detecting network attacks,World Applied Sciences Journal,V-27,I-11,PP-1461-1465,Y-2013

7. Tariq J., Kumaravel A.,Construction of cellular automata over hexagonal and triangular tessellations for path planning of multi-robots,2016 IEEE International Conference on Computational Intelligence and Computing Research, ICCIC 2016,V-,I-,PP--,Y-2017

8. Sudha M., Kumaravel A.,Analysis and measurement of wave guides using poisson method,Indonesian Journal of Electrical Engineering and Computer Science,V-8,I-2,PP-546-548,Y-2017

9. Ayyappan G., Nalini C., Kumaravel A.,Various approaches of knowledge transfer in academic social network, International Journal of Engineering and Technology,V-,I-,PP-2791-2794,Y-2017

10. Kaliyamurthie, K.P., Sivaraman, K., Ramesh, S. Imposing patient data privacy in wireless medical sensor networks through homomorphic cryptosystems 2016, Journal of Chemical and Pharmaceutical Sciences .

11. Kaliyamurthie, K.P., Balasubramanian, P.C.An approach to multi secure to historical malformed documents using integer ripple transfiguration 2016 Journal of Chemical and Pharmaceutical Sciences 9

12. A.Sangeetha,C.Nalini,"Semantic Ranking based on keywords extractions in the web", International Journal of Engineering \& Technology, 7 (2.6) (2018) 290-292

13. S.V.GayathiriDevi,C.Nalini,N.Kumar,"An efficient software verification using multi-layered software verification tool "International Journal of Engineering \& Technology, 7(2.21)2018 454-457 
14. C.Nalini,ShwtambariKharabe,"A Comparative Study On Different Techniques Used For Finger - Vein Authentication", International Journal Of Pure And Applied Mathematics, Volume 116 No. 8 2017, 327-333, Issn: 1314-3395

15. M.S. Vivekanandan and Dr. C. Rajabhushanam, "Enabling Privacy Protection and Content Assurance in Geo-Social Networks", International Journal of Innovative Research in Management, Engineering and Technology, Vol 3, Issue 4, pp. 49-55, April 2018.

16. Dr. C. Rajabhushanam, V. Karthik, and G. Vivek, "Elasticity in Cloud Computing", International Journal of Innovative Research in Management, Engineering and Technology, Vol 3, Issue 4, pp. 104-111, April 2018.

17. K. Rangaswamy and Dr. C. Rajabhushanamc, "CCN-Based Congestion Control Mechanism In Dynamic Networks", International Journal of Innovative Research in Management, Engineering and Technology, Vol 3, Issue 4, pp. 117-119, April 2018.

18. Kavitha, R., Nedunchelian, R., "Domain-specific Search engine optimization using healthcare ontology and a neural network backpropagation approach”, 2017, Research Journal of Biotechnology, Special Issue 2:157-166

\section{AUTHORS PROFILE}

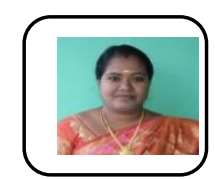

DVimala Assistant Professor, Department of Computer Science \& Engineering, Bharath Institute of Higher Education and Research, Chennai, India

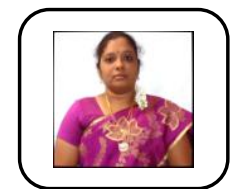

P.Nandhini Assistant Professor, Department of Computer Science \& Engineering, Bharath Institute of Higher Education and Research, Chennai, India

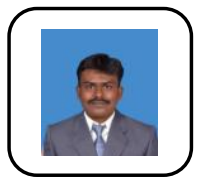

R.Elankavi Assistant Professor, Department of Computer Science \& Engineering, Bharath Institute of Higher Education and Research, Chennai, India 